\title{
A AULA DE FUNDAMENTOS DA EDUCAÇÃO INFANTIL: POSSIBILIDADES METODOLÓGICAS
}

\author{
Carlos Alberto Lima de Oliveira Pádua ${ }^{1}$
} Antonia Dalva França-Carvalho ${ }^{2}$

\section{CONSIDERAÇÕES INICIAIS}

A vida universitária perpassa muito além do que possamos imaginar quando nos referimos à sala de aula e as metodologias que utilizamos para concretizar as aulas. A mesma é um espaço de vivências, onde alunos e professores buscam de forma insaciada o conhecimento e a construção de saberes necessários para o desenvolvimento pessoal, social e principalmente profissional.

É nessa perspectiva que as relações interpessoais dentro da Universidade e da própria sala de aula se entrelaçam em um só objetivo que é formar sujeitos autônomos, tendo como referência os saberes e aprendizados construídos e reconstruídos por eles.

Dessa forma, faz-se necessário que o professor universitário como um mediador de conhecimento procure está atento às metodologias utilizadas no desenvolver de suas aulas, pois, é através dessas técnicas que seu trabalho despertará o interesse no aluno que espera muito além de um simples momento.

Sabemos que ensinar requer de quem ensina paciência e acima de tudo criatividade. Também, é muito importante o empenho e desempenho do professor no momento de trabalhar os conteúdos e dessa forma garantir a consolidação da aprendizagem do seu alunado.

Essa ideia que parece óbvia na verdade contêm certas nuances sobre as quais podemos refletir quando se trata das metodologias utilizadas para a reflexão dos conteúdos no espaço universitário, já que envolve o trabalho docente no intuito

\footnotetext{
1 Doutorando em Educação, pelo Programa de Pós-Graduação em Educação (PPGEd), da Universidade Federal do Piauí. Coordenador Pedagógico da Educação Básica. Pesquisador do Núcleo Interdisciplinar de Pesquisas em Educação e Epistemologia da Prática Profissional (NIPEEPP). E-mail: calopadua1@hotmail.com

2 Doutora em Educação. Professora do Programa em Pós-Graduação em Educação da UFPI e do Departamento de Fundamentos da Educação, do Centro de Ciências da Educação, da Universidade Federal do Piauí. Presidente da Comissão de Governança dos Programas de Formação Inicial de Professores, da Universidade Federal do Piauí. Líder do Núcleo Interdisciplinar de Pesquisas em Educação e Epistemologia da Prática Profissional (NIPEEPP). E-mail: adalvac@uol.com.br.
} 
de promover resultados no desenvolvimento do discente e consequentemente na sua formação.

É nesse intuito que o presente artigo ${ }^{3}$ tem como objetivo descrever as metodologias desenvolvidas durante as aulas ministradas na disciplina de Fundamentos da Educação Infantil para a turma do terceiro período noturno (2016/2) do curso de Licenciatura em Pedagogia da Universidade Federal do Piauí - UFPI e relatar a vivência que o tirocínio docente proporciona aos mestrandos do Programa de Pós-Graduação em Educação (PPGEd) dessa Instituição de Ensino Superior (IES).

O tirocínio docente é a oportunidade que o aluno de pós-graduação tem em desenvolver os conhecimentos para o caminho da docência, em um trabalho organizado e desenvolvido pelo orientador, oportunizando a troca de conhecimentos e experiências no Ensino Superior.

\section{A DISCIPLINA DE FUNDAMENTOS DA EDUCAÇÃO INFANTIL DA UFPI}

A disciplina descrita é ofertada pelo Centro de Ciências da Educação - CCE, especificamente pelo Departamento de Fundamentos da Educação - DEFE e está inserida no currículo do curso de Licenciatura em Pedagogia, com carga horária de 60 horas, sendo desenvolvida no turno da noite pela Prof. ${ }^{-}$Dra. Antonia Dalva França Carvalho.

O plano de ensino em seu ementário apresenta a seguinte estruturação: "Educação Infantil: aspectos históricos e legais; Desenvolvimento moral; O brincar e o desenho na Educação Infantil". A partir desse princípio foi analisada e refletida a bibliografia para poder ser realizada uma correlação com os objetivos, conteúdos, metodologia e o processo avaliativo. Essa sistematização de ideias foi essencial para o planejamento do trabalho que foi realizado pela professora, o aluno da pósgraduação e os 31 (trinta e um) discentes envolvidos no lócus da aprendizagem.

É no espaço do diálogo e do conflito, constituído por sujeitos criativos e desejosos de liberdade, que as mudanças são forjadas, diuturnamente. A aula constitui, por conseguinte, um lugar privilegiado para o processo de

\footnotetext{
${ }^{3}$ Este artigo possui sua versão original publicada na obra FRANÇA-CARVALHO, A. D. et al. (org.) Notas de aula: dialogando sobre práticas de aprendizagens na escola e na universidade. Teresina, EDUFPI, 2017.
} 
aprendizagem, pois nesse espaço-tempo professores e alunos podem desenvolver ações interativas de forma a transformá-la em um campo de debates sobre os temas em foco (FARIAS et al, 2014, p. 166).

De acordo com essa prerrogativa, foi possível desenvolver os objetivos da disciplina, partindo da discussão entre os pares, para a obtenção de uma reflexão crítica. Por conseguinte, a estrutura física e os recursos ofertados pela instituição puderam subsidiar o processo de interação entre os participantes da aula, facilitando o processo de ensino e aprendizagem. E como estratégia de atividade, foi trabalhado dia após dia um modelo diferente de estrutura de aula, tornando diversificado cada encontro. "Para tanto, a formação, mais que ensinar ou formar, deveria criar situações e espaços de reflexão e formação; mudar a metodologia" (IMBERNÓN, 2016, p. 168).

\title{
3 OS CONTEÚDOS MINISTRADOS DURANTE AS AULAS
}

Para chegar a concretização e atingir os objetivos da disciplina ministrada é preciso ter noção e domínio sobre os conteúdos e assim, tornar satisfatório o conhecimento principalmente quando se trata do ensino superior como bem destaca Suhr e Silva (2012, p. 71).

\begin{abstract}
Os conteúdos são as formas culturais e consideradas essenciais numa determinada época para a vida em sociedade e, no caso do ensino superior, para o exercício de determinada profissão. Não se trata, apenas, do ensino de conceito, embora estes continuem sendo essenciais. É preciso também ensinar e desenvolver procedimentos e atitudes, elementos que anteriormente não eram considerados objetos do trabalho pedagógico no ensino superior.
\end{abstract}

É por essa razão que se faz necessário e importante que os conteúdos passem a ser trabalhados de forma organizada para se tornarem significativo, prazeroso e oportunizando o contato direto com cada unidades ofertada. O Quadro 1 a seguir traz os conteúdos que foram abordados durante o desenvolvimento da disciplina. 
Quadro 1 - Conteúdos trabalhados em sala de aula.

\begin{tabular}{|c|c|c|c|}
\hline UNIDADE I & UNIDADE II & UNIDADE III & UNIDADE VI \\
\hline $\begin{array}{l}\text { Educação Infantil: } \\
\text { aspectos históricos, } \\
\text { políticos e legais: } \\
\text { - Evolução histórica da } \\
\text { Educação Infantil; } \\
\text { - Concepções de infância } \\
\text { e de Educação Infantil; } \\
\text { - Profissionais da } \\
\text { Educação Infantil: } \\
\text { formação e atuação. }\end{array}$ & 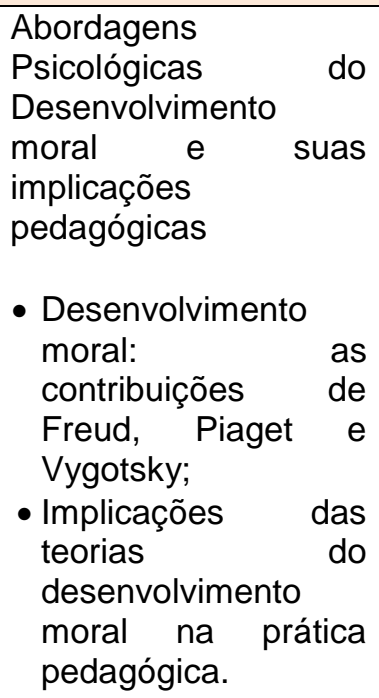 & $\begin{array}{l}\text { Abordagens } \\
\text { Psicológicas do } \\
\text { Brincar e suas } \\
\text { implicações } \\
\text { pedagógicas: } \\
\text { - Abordagem } \\
\text { Psicanalítica } \\
\text { brincar; } \\
\text { - Abordagem } \\
\text { construtivista } \\
\text { brincar; } \\
\text { - Abordagem } \\
\text { histórico-cultural do } \\
\text { brincar. }\end{array}$ & $\begin{array}{l}\text { O desenho na } \\
\text { Educação Infantil: } \\
\text { - O desenho } \\
\text { infantil e suas } \\
\text { relações nos } \\
\text { processos de } \\
\text { desenvolvimento } \\
\text { e aprendizagem; } \\
\text { - Mediação } \\
\text { pedagógica e } \\
\text { desenho infantil. }\end{array}$ \\
\hline
\end{tabular}

Fonte: Plano de Ensino da disciplina Fundamentos da Educação Infantil, 2016.

Partindo desse pressuposto e com as orientações dadas sobre cada unidade foi possível estabelecer um ensino gradual e satisfatório como ressalta Freire (1996, p. 95) "o ensino dos conteúdos implica o testemunho ético do professor" que sendo ele professor e mediador de conhecimentos é também o responsável pelo que levar para suas aulas. A seguir são destacadas as experiências construídas e desenvolvidas no contexto da sala.

\section{RELATO DE EXPERIÊNCIA: UM OLHAR SOBRE A SALA DE AULA}

A primeira aula apresentamos a disciplina Fundamentos da Educação Infantil e que a mesma seria trabalhada por dois professores, a professora titular da disciplina e o aluno do mestrado, onde esse, através da disciplina - Atividade Orientada: Tirocínio Docente I, que consta como componente curricular do Mestrado em Educação, foi inserido no processo formativo da disciplina em foco para obter experiência educativa, no contexto da Educação Superior e aprender diretamente na relação orientadora e orientando.

Logo após esse momento inicial, explicamos uma dinâmica de apresentação, no intuito que todos ficassem tranquilo e passassem a se conhecer melhor, assim foi orientado aos presentes para se acomodar em dupla e trocar informações que julgassem necessárias e que depois, cada um falaria sobre o colega. Após um 
tempo necessário, cada dupla foi convidada a se apresentar, onde foi possível conhecermos várias características, dificuldades e anseios dos alunos e professores. Foi um momento divertido, descontraído e importante para a interação do grupo.

Em seguida, através de um ato democrático construímos coletivamente 0 "contrato didático/pedagógico", compreendido com um pacto entre professores e alunos objetivando como define Charlot (2000) mobilização para o saber. Ainda, através do diálogo e sugestões entre docentes e discentes, foi possível organizar uma lista que norteasse o processo das aulas, sendo perceptível o consenso de ideias por ambas as partes e assim, firmar uma relação saudável entre todos, como destaca Lowman (2004) a construção dos vínculos entre professor e aluno perpassa pelo conhecimento, mas especificamente no que tange 0 desenvolvimento sociocognitivo do estudante do ensino superior, que se encontra em fase adulta. Nesse momento foi possível destacar no documento os princípios do respeito, o saber ouvir e a ética em sala de aula, para o bom desenvolvimento do ensino e aprendizagem.

Durante o primeiro encontro observamos que muitos deles chegavam cansados devido o trabalho, nos levando a refletir e reavaliar sobre as atividades no intuito de torná-las mais práticas e dinâmicas para que houvesse o envolvimento entre professores e alunos.

No segundo encontro fizemos a leitura do plano de ensino, onde discutimos os seguintes pontos: identificação, ementa, objetivos, conteúdo programático, procedimentos de ensino, sistemática de avaliação, e bibliografia básica e complementar. Durante a discussão, pudemos ouvir os desejos, desafios e expectativas dos alunos referentes à disciplina, e como consequência procuramos sanar as dúvidas inerentes às atividades e deixá-los mais tranquilos.

$\mathrm{Na}$ oportunidade aplicamos a atividade diagnóstica escrita no intuito de conhecermos as experiências individuais e as ideias iniciais dos alunos sobre 0 contexto a ser estudado durante o período, e também como forma de orientar nosso trabalho, sendo um direcionamento para a ressignificação da nossa prática docente, até mesmo porque a prática avaliativa é dinâmica e envolve a prudência como destaca Hoffmann (1994). Assim, solicitamos que os alunos discorressem sobre as seguintes indagações como consta no Quadro 2 com às questões diagnóstica aplicadas na turma. 
Quadro 2 - Atividade diagnóstica.

\begin{tabular}{|l|l|}
\hline 01 & Com base em suas experiências conceitue Educação. \\
\hline 02 & O que você considera imprescindível para se determinar os objetivos da educação? \\
\hline 03 & Como você conceitua criança? \\
04 & Qual o papel da brincadeira no desenvolvimento infantil? \\
\hline 05 & O que é aprendizagem? \\
\hline 06 & Quais as concepções de desenvolvimento e aprendizagem que permeiam as práticas \\
& pedagógicas? \\
\hline 07 & Quais são as suas perspectivas em relação à disciplina Fundamentos da Educação Infantil? \\
\hline
\end{tabular}

Fonte: Autores, 2016.

A atividade acima nos proporcionou um panorama sobre os conhecimentos prévios dos alunos acerca do conceito de Educação. E ainda de acordo com o plano de ensino, destacamos as técnicas de como iriamos trabalhar os conteúdos, isto é: "aulas expositivas e dialogadas, trabalhos individuais e em grupo, leituras, debates, seminários, exibição de filmes/documentários, trabalhos teóricos e teórico-práticos". $\mathrm{Na}$ oportunidade reafirmamos que "a metodologia da disciplina privilegia a leitura, pressuposto básico à apropriação do conhecimento, portanto, indispensável ao aluno a aquisição e a leitura atenta e cuidados dos textos".

As aprendizagens nesse dia caracterizaram uma forma interessante de trabalhar a prática docente em sala de aula, tendo como foco a aprendizagem significativa dos alunos. Pudemos perceber também as suas fragilidades, muitas vezes pela disponibilidade restrita de tempo para os estudos necessários, pois muitos deles trabalham durante os turnos manhã e tarde.

Como destacamos na forma de um quadro os conteúdos a serem trabalhados no decorrer das regências passaremos a destacar todas as unidades que foram trabalhadas especificamente em cada encontro.

No subitem "Evolução histórica da Educação Infantil", trabalhamos com um diferencial, pois decidimos entregar previamente para os alunos os textos iniciais como forma de motivá-los e instigá-los para uma leitura reflexiva para que os mesmos se familiarizassem com conteúdo da disciplina. Durante a abordagem em sala de aula, utilizamos como recursos o notebook e datashow para apresentarmos os tópicos dos textos que direcionaram a discussão, concordando com a ideia de 
Stahlschmidt (2009) que destaca a importância das tecnologias da comunicação para a atividade do professor referente a produção do saber.

A leitura prévia do conteúdo proporcionou uma ampla discussão, onde todos puderam participar, ou seja, fazendo questionamentos, apresentando seus entendimentos, percebendo situações e recriando novos conceitos acerca de determinadas situações.

Ao final da discussão do conteúdo foi proposta uma atividade individual para os alunos na intenção de uma melhor aprendizagem, onde todos sintetizariam um texto indicado e apresentá-lo na próxima aula. Para o encontro seguinte foi disponibilizado o material antecipado a ser trabalhado com objetivo que todos fizessem uma leitura prévia do conteúdo.

O encontro seguinte, fizemos uma retomada do assunto abordado na unidade anterior e solicitamos a quatro alunos que fizessem a leitura da síntese do texto tecendo comentários e compartilhando suas reflexões com o grupo. Em seguida, utilizamos a projeção de slides para apresentar algumas imagens importantes que representaria a exposição descrita pelo texto, levando os alunos a visualizarem através da arte o que o autor delineou em seus escritos.

Ainda sobre o conteúdo "Concepções de infância e de Educação Infantil", fizemos uma abordagem geral dos textos e em seguida foi proposto uma atividade em grupo, para que os alunos construíssem um painel e logo após fizessem a apresentação do mesmo. Os grupos foram por eles mesmos definidos, sendo que os materiais necessários para a produção do painel foram entregues pelos professores, tais como: papel madeira, pincéis coloridos, lápis de cor, canetas, papel A4 colorido, cola e tesoura.

Os alunos se dispuseram da forma que Ihes achavam conveniente para a confecção dos painéis. Uns exploraram o chão da sala, outros desenhavam sobre a mesa e outros uniram as cadeiras para produzir o material. O que era apenas uma atividade tornou-se em momento significativo e rico de compreensão do conteúdo abordado e de novas aprendizagens referente ao assunto, pois os alunos expressaram suas emoções, percepções e opiniões em exemplos através da arte manual como mostra as figuras abaixo. 
Figura 1 - Construção do painel

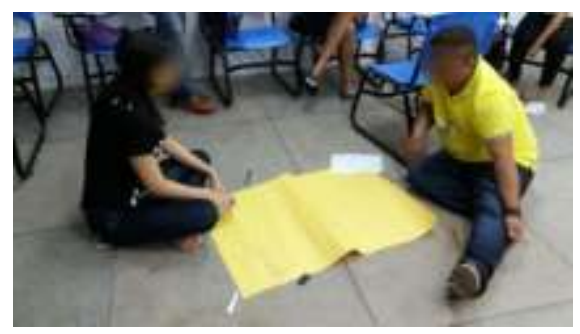

Fonte: Autores, 2016.

Figura 3 - Apresentação do painel

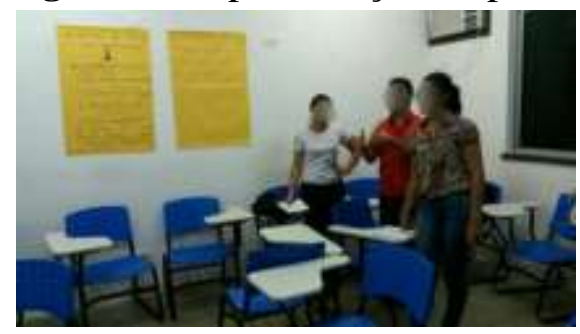

Fonte: Autores, 2016.
Figura 2 - Discussão sobre a temática

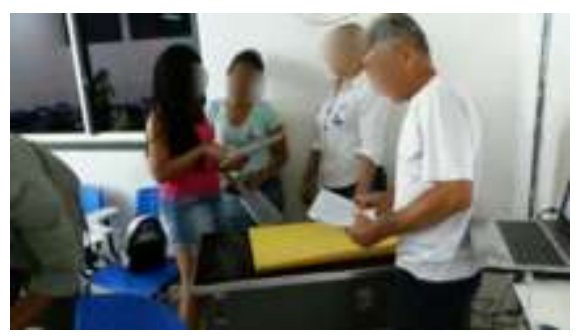

Fonte: Autores, 2016.

Figura 4 - Exposição do painel

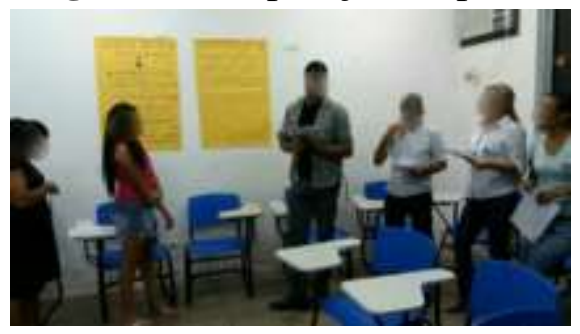

Fonte: Autores, 2016.

Finalizado a produção dos painéis, solicitamos a apresentação das equipes para expor suas obras. Após cada apresentação as considerações eram feitas grupalmente, ou seja, entre professores e alunos, tornando assim, a troca de saberes e experiências indispensáveis para uma autonomia do saber-fazer. Sobre essa abordagem, pode ser destacado que "Tanto na gestão da matéria como na gestão de sala de aula, o professor como mediador pedagógico detém autonomia, sendo esta determinada por exigências de responsabilidade, competência e controle na satisfação dos objetivos perseguidos" (FRANÇA-CARVALHO, 2007, p. 82-83).

No encontro posterior, apresentamos uma reflexão sobre os "Profissionais da Educação Infantil: formação e atuação", através dos textos. Logo após, solicitamos aos alunos que se reunissem em cinco grupos da forma que desejassem, e distribuímos os textos para que em equipe pudessem fazer um estudo e análise, buscando destacar os pontos relevantes. Mas era necessária uma atividade que despertasse a atenção dos alunos, pois alguns desses durante as aulas anteriores reclamavam do cansaço ocasionado pelo trabalho para o sustento pessoal e/ou familiar. Nesse sentido, Madeira e Silva (2015) descreve sobre a necessidade do professor em organizar estratégias que instigue a leitura pelos alunos durante as aulas. 
Baseado nesse direcionamento e antes de iniciarem a leitura, explicamos a atividade proposta, que consistiria em descrever o texto lido em uma carta pedagógica e enviá-las para duas Pedagogas de dois Centros Municipais de Educação Infantil - CMEl's, da cidade de Teresina-Piauí. Foi orientado que nessa carta deveria abordar os seguintes aspectos: a identificação do grupo, apresentação do texto, alguns questionamentos, a solicitação de respostas e finalmente os agradecimentos. Assim, distribuímos os envelopes e folhas impressas com linhas aos grupos, na quantidade que fosse necessária, sem o limite de laudas, como é demonstrado nas figuras a seguir.

Figura 5 - Produção da carta pedagógica

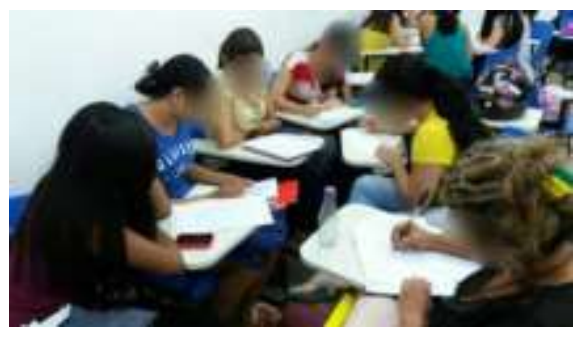

Fonte: Autores, 2016.
Figura 6 - Reflexão acerca da carta

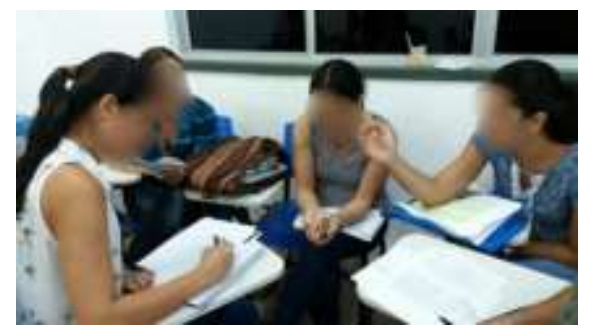

Fonte: Autores, 2016.

Observamos que a produção da atividade estava seguindo um bom desenvolvimento como planejada. Informamos posteriormente que a apresentação das cartas aconteceria na aula seguinte e encerramos o encontro destacando como iria se dá o processo avaliativo. Dialogamos que seria o conjunto do que havíamos produzidos e vivenciados no decorrer das regências como, por exemplo: a síntese do texto, confecção e apresentação do painel e a carta pedagógica.

Já para introduzir o conteúdo dos subitens: "Desenvolvimento moral: contribuições de Freud, Piaget e Vygotsky" e "Implicações das teorias do desenvolvimento moral na prática pedagógica", apresentamos um vídeo para que os alunos refletissem sobre a temática que seria futuramente abordada. Em seguida, analisamos o contexto apresentado nas imagens e realizamos uma discussão sobre dois textos.

E como forma de uma atividade que desenvolvesse a criação/inovação, a elaboração em equipe, como sugere Coutinho (2002) e melhorar a aprendizagem, solicitamos que os alunos se dividissem em cinco grupos e fizessem a apresentação do conteúdo em forma de varal didático. Foi explicado que descreveriam em papel 
A4 os tópicos abordados pelos autores e que posteriormente seriam apresentados a todos na sala de aula. Para a realização da atividade, utilizamos materiais como: papel A4 colorido, pincéis, cola, tesoura dentre outros materiais pedagógicos para que fossem utilizados através da criatividade dos alunos.

Partindo desse princípio, a atividade foi realizada em parceria, com prazer e harmonia entre todos, incluindo os professores. No entanto, não foi possível a apresentação no mesmo dia pelo fato que a produção do material exigiu um determinado tempo, sendo assim solicitada a exposição no próximo encontro. $\mathrm{Na}$ aula seguinte, fizemos a retomada dos textos anteriores através da utilização do varal didático pelos grupos e nessa aula foi possível uma maior discussão em busca de uma compreensão acerca do conteúdo explorado. As Figuras 7 e 8 demonstram o momento da apresentação do conteúdo através do varal didático.

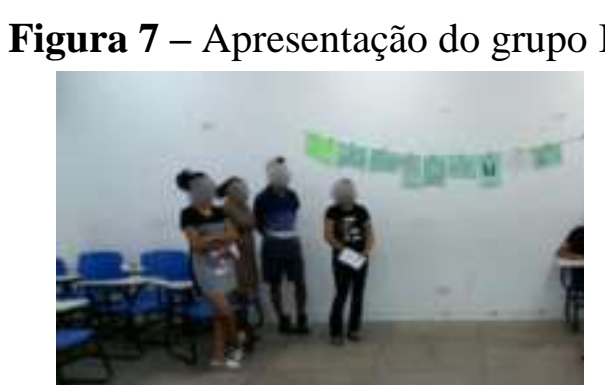

Fonte: Autores, 2016.
Figura 8 - Apresentação do grupo II

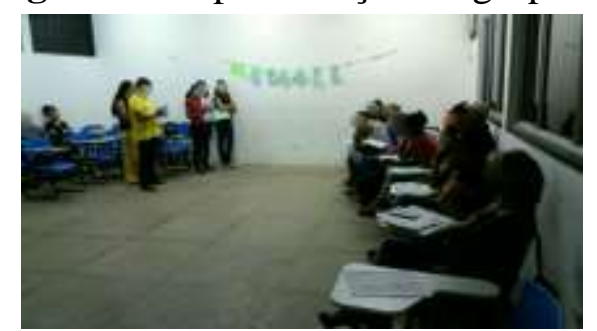

Fonte: Autores, 2016.

As Unidades III - "Abordagens Psicológicas do Brincar e suas implicações pedagógicas" e IV - "O desenho na Educação Infantil", tiveram como proposta a organização dos seminários desenvolvidos pelos alunos, e para tantos foram listados alguns pontos que deveriam ser levados em consideração, sendo assim elencados: planejamento, pontualidade nas apresentações, dinâmica, a parceria, criatividade e o domínio do conteúdo. Nesse sentido, foi possível concluir as unidades de acordo com o plano apresentado no início da disciplina Fundamentos da Educação Infantil.

\section{CONSIDERAÇÕES FINAIS}


Durante o referido período letivo, foi possível conhecer novas leituras e desenvolver consequentemente prazerosas aprendizagens. Resultado desse processo interativo entre professora, aluno do mestrado e discentes, foram as atividades desenvolvidas em sala de aula, para tornar motivador cada encontro semanal.

Buscavam-se incessantemente possibilidades metodológicas desafiadoras e que fossem aliadas ao conteúdo, sempre na intencionalidade de cultivar o processo de ensino e aprendizagem com qualidade, onde todos pudessem buscar novos saberes a partir daquelas situações vivenciadas em sala de aula.

Assim, a aula é de fato uma atividade de produção de conhecimento e inovação, em que professores e alunos estão em constante interação para que o conhecimento seja adquirido com ética e dedicação para que o processo formativo torne-se com menos dificuldades e com mais resultados satisfatórios na formação e transformação das pessoas.

\section{REFERÊNCIAS}

COUTINHO, Regina Maria Teles. A prática pedagógica do professor formador: desafios e perspectivas de mudanças. Teresina: Halley, 2002.

CHARLOT, Bernard. A escola e o saber. Entrevista ao centro de Referência em Educação Maio Covas: Disponível em:

<http://www.crmariocovas.sp.gov.br/ent_a.php?=006> Acesso em: 14 fev.2017

FARIAS, Isabel Maria Sabino de [et. al.]. Didática e docência: aprendendo a profissão. 4. ed. Brasília: Líber Livro, 2014.

FRANÇA-CARVALHO, Antonia Dalva. A Racionalidade pedagógica da ação dos formadores de professores: um estudo sobre a epistemologia da prática docente nos cursos de licenciatura da Universidade Federal do Piauí. 2007, 239 p. Tese (Doutorado em Educação). UFC, Fortaleza, 2007.

FREIRE, P. Pedagogia da autonomia: saberes necessários à prática educativa. São Paulo: Paz e Torres, 1996.

HOFFMANN, Jussara. Avaliação mito \& desafio: uma perspectiva construtivista. Porto Alegre: Mediação, 1994.

IMBERNÓN, Francisco. Qualidade do ensino e formação do professorado: uma mudança necessária. [tradução Silvana Cobucci Leite]. - São Paulo: Cortez, 2016. 
LOWMAN, J. Dominando as técnicas de ensino. São Paulo: Atlas, 2004.

PÁDUA, C. A. L. de O.; FEITOSA, M. S. A.; FRANÇA-CARVALHO, A. D. A aula de fundamentos da educação infantil: possibilidades metodológicas. In: FRANÇACARVALHO, A. D. et al. (org.) Notas de aula: dialogando sobre práticas de aprendizagens na escola e na universidade. Teresina, EDUFPI, 2017. p.98-112.

MADEIRA, Miguel Carlos; SILVA, Rosa Maria Alves da. Ensinar na universidade: didática para professores iniciantes. Petrópolis, RJ: Vozes, 2015.

STAHLSCHMIDT, Rosângela Maria. Formação inicial e formação continuada. In: RANKEL, Luiz Fernando; STAHLSCHMIDT, Rosângela Maria. Profissão Docente. Curitiba: IESDE Brasil S.A., 2009. 